\title{
Association of adiponectin polymorphism with cord blood adiponectin concentrations and intrauterine growth
}

\author{
Makoto Saito $^{1}$, Tomohiro Kamoda ${ }^{1}$, Kazunori Nishimura ${ }^{1}$, Yayoi Miyazono ${ }^{1}$, Yu Kanai ${ }^{1}$, Yoshiaki Kato ${ }^{1}$, \\ Atsushi Iwabuchi ${ }^{1}$, Hiroko Fukushima ${ }^{1}$, Hiromi Hamada ${ }^{2}$, Tadao Arinami ${ }^{3}$, Ryo Sumazaki ${ }^{1}$ and \\ Emiko Noguchi ${ }^{3,4}$
}

To assess whether adiponectin gene (ADIPOQ) polymorphism is associated with intrauterine fetal growth and cord blood adiponectin, we investigated eight single-nucleotide polymorphisms (SNPs; rs182052, rs710445, rs16861205, rs12495941, rs 1501299, rs3774261, rs2082940 and rs266729) in ADIPOQ and birth weight and cord blood adiponectin in 526 healthy neonates. We found that the neonates carrying the $G$ allele of rs 266729 had a significantly greater birth weight s.d. score than those homozygous for the C allele (CC: $-0.06 \pm 0.75$ versus CG: $0.20 \pm 0.64$ versus GG: $0.07 \pm 0.78 ; P=1.65 \times 10^{-3}$, adjusted $\left.P=9.90 \times 10^{-3}\right)$. However, this difference was not significant after adjustment for cord blood adiponectin $(P=0.04$, adjusted $P=0.26$ ). The rs266729 SNP was strongly associated with cord blood adiponectin; neonates with rs $266729 \mathrm{GG}$ had the highest adiponectin (CC: $34.1 \pm 20.2$ versus CG: $44.3 \pm 26.1$ versus GG: $54.1 \pm 36.7 \mu \mathrm{ml}^{-1}, P=2.80 \times 10^{-9}$, adjusted $\left.P=1.68 \times 10^{-8}\right)$. This association remained after adjustment for birth weight s.d. score $\left(P=6.63 \times 10^{-8}\right.$, adjusted $P=3.98 \times 10^{-7}$ ). Our results suggest that the influence of the rs266729 SNP in ADIPOQ on birth weight may be dependent on circulating adiponectin.

Journal of Human Genetics (2012) 57, 109-114; doi:10.1038/jhg.2011.134; published online 24 November 2011

Keywords: adiponectin; $A D I P O Q$ gene; intrauterine growth; polymorphism

\section{INTRODUCTION}

Adiponectin is a protein derived from adipose tissue in humans, and serum adiponectin levels are paradoxically reduced in obese individuals. ${ }^{1}$ Circulating adiponectin concentrations are inversely correlated with body weight and fat mass content in human adults. ${ }^{1}$ Decreased concentrations of adiponectin are also seen in patients with insulin resistance or type 2 diabetes mellitus. ${ }^{2}$ Insulin-sensitizing agents such as thiazolidinediones increase adiponectin concentrations in both humans and animals, whereas the administration of adiponectin increases insulin sensitivity in animals. ${ }^{3,4}$ Also, adiponectin is postulated to play a role in the modulation of glucose and lipid metabolism in insulin-sensitive tissues. ${ }^{5}$

Fetal growth is to a great extent controlled by the actions of insulin, and adiponectin, as a key regulator of insulin sensitivity, can be expected to have significant effects on fetal growth. ${ }^{6,7}$ Some investigators have reported a significant positive relationship between birth weight, as a proxy mirror of the intrauterine environment, and cord blood adiponectin levels. ${ }^{8-10}$ Our previous study demonstrated that the serum adiponectin levels on the first day of life were significantly higher in appropriate-for-gestational-age birth weight (AGA) than in small-for-gestational-age birth weight (SGA) term neonates. ${ }^{11}$ Although adiponectin levels in the cord blood of term infants are extensively higher than in children or adults, its exact physiological role in regulating intrauterine fetal growth has not been fully elucidated. ${ }^{8,9,12}$ On the other hand, epidemiological studies have revealed that there is a relationship between fetal growth retardation and the subsequent development of insulin resistance later in life. ${ }^{13,14}$

Single-nucleotide polymorphisms (SNPs) in the adiponectin gene $(A D I P O Q)$ have been associated with adiponectin levels, changes in insulin sensitivity and risk for type 2 diabetes mellitus and coronary artery disease. ${ }^{15-18}$ The present study was undertaken to assess whether the ADIPOQ polymorphism is associated with birth size and cord blood adiponectin levels in Japanese neonates.

\section{MATERIALS AND METHODS}

Subjects and genomic DNA extraction

A total of 526 healthy neonates (264 males and 262 females, gestational age, 35-41 weeks and birth weight $>2000$ g), born at Tsukuba University Hospital

${ }^{1}$ Department of Pediatrics, Graduate School of Comprehensive Human Sciences, University of Tsukuba, Ibaraki, Japan; ${ }^{2}$ Obstetrics and Gynecology, Graduate School of Comprehensive Human Sciences, University of Tsukuba, Ibaraki, Japan; ${ }^{3}$ Medical Genetics, Graduate School of Comprehensive Human Sciences, University of Tsukuba, Ibaraki, Japan and ${ }^{4}$ Japan Science and Technology Agency, Core Research for Evolutional Science and Technology (CREST), University of Tsukuba, Ibaraki, Japan.

Correspondence: Dr T Kamoda, Department of Pediatrics, Graduate School of Comprehensive Human Sciences, University of Tsukuba, 1-1-1 Tennoudai, Tsukuba 305-8575, Ibaraki, Japan. 
were included in the study. Table 1 shows the baseline characteristics of 526 neonates. The recruitment was carried out between September 2009 and March 2011. Gestational age was calculated according to the date of the mother's last menstrual period and was also determined using fetal ultrasonography. All neonates were AGA, and had no severe asphyxia, congenital malformations or respiratory disorder at birth. AGA was defined as a birth weight between -2.0 and +2.0 s.d. according to Japanese standards. ${ }^{19}$ Birth weight s.d. was calculated according to the reference standard for gestational age in Japanese newborns. ${ }^{19}$ Neonates whose mothers had hypertension, diabetes mellitus or any chronic disease causing placental dysfunction or fetal growth restriction, or had received medication during pregnancy causing placental dysfunction or fetal growth restriction, including glucocorticoids, were excluded. All neonates included in this study were singletons, and none had a diagnosis of asphyxia (5-min Apgar score $<8$ ) or neonatal complications. A total of 99 neonates were born with cesarean section and 427 with vaginal delivery. Cord blood samples were collected immediately after delivery and were aliquoted and frozen at $-80^{\circ} \mathrm{C}$ until analysis. Genomic DNA was isolated from cord blood leukocytes using a DNA purification kit (Promega, Madison, WI, USA). The study was approved by Tsukuba University Ethics Committee, and written informed consent was obtained from all parents whose neonates were examined.

\section{Anthropometric measurements}

General physical measurements, including body weight, length and head circumference, were determined at birth by experienced midwives. The body weight of each neonate and placenta weight were determined to the nearest $1 \mathrm{~g}$ using an electronic scale. The body length and head circumferences were measured with a tape measure to the nearest $0.1 \mathrm{~cm}$. The neonatal ponderal index was calculated as weight $(\mathrm{kg})$ per body length ${ }^{3}\left(\mathrm{~m}^{3}\right)$, respectively. Self-reported mother's body weight and height before pregnancy were obtained, and the mother's body mass index was calculated as weight $(\mathrm{kg})$ per body length ${ }^{2}\left(\mathrm{~m}^{2}\right)$.

\section{Cord blood concentrations of adiponectin}

The plasma adiponectin concentration was assayed with an ELISA kit (Linco Research, St Chales, MO, USA) following the manufacturer's instruction. The sensitivity of the assay was $1 \mu \mathrm{g} \mathrm{ml}^{-1}$ and the limit of linearity was $250 \mu \mathrm{g} \mathrm{ml}^{-1}$. Inter- and intra-assay coefficients of variation were $6.9-9.3 \%$ and $1.8-6.2 \%$, respectively.

\section{ADIPOQ genotyping}

Genotype data of the Japanese population for the $A D I P O Q$ region were obtained from the HapMap website (http://www.hapmap.org/), and tag SNPs were selected using the Tagger software implemented in the Haploview software, with an $r^{2}$ threshold of 0.8 and allele frequencies of $0.1 .^{20,21}$ Seven SNPs (rs182052, rs710445, rs16861205, rs12495941, rs1501299, rs3774261 and rs2082940) were selected as tag SNPs, and one 5' upstream SNP (rs266729), which has been reported to be associated with cord blood adiponectin concentration in German neonates, was also subjected to genotyping. ${ }^{22}$ These eight SNPs were genotyped using the TaqMan Assay-on-Demand SNP Typing System (Applied Biosystems, Foster City, CA, USA) following the manufacturer's instructions. The reaction was performed in a 384-well format using $5 \mathrm{ng}$ of genomic DNA. The plates were then placed on a thermal cycler (GeneAmp 9700 PCR systems, Life Technologies, Carlsbad, CA, USA) and heated to $95^{\circ} \mathrm{C}$ for $10 \mathrm{~min}$, followed by 60 cycles of $92^{\circ} \mathrm{C}$ for $15 \mathrm{~s}$ and $60^{\circ} \mathrm{C}$ for $1 \mathrm{~min}$. The end point fluorescence readings were performed using ABI Prism 7900 HT System and SDS software 2.2.0 (Life Technologies).

\section{Statistical analysis}

The results are expressed as means \pm s.d. unless otherwise stated. Student's $t$-test, $\chi^{2}$ test and ANCOVA were performed to assess baseline characteristics. Relationships between the cord blood adiponectin levels and baseline parameters were evaluated using Pearson's correlation coefficient test. To investigate independent predictors of the cord blood adiponectin, a multiple regression analysis was performed considering the variables maternal age, parity, prepregnancy maternal body mass index, placental weight and mode of delivery. All analyses mentioned above were performed using Stat View 5.0 (SAS Institute, Cary, NC, USA, 1998). A level of $P<0.05$ was considered statistically significant. In the genotyping experiment, deviations from the predicted Hardy-Weinberg equilibrium were determined using the $\chi^{2}$ test. Association analyses were performed assuming a log-additive effect for each polymorphism with SNPassoc software. ${ }^{23}$ Multiple tests were corrected by the method proposed by $\mathrm{Li}$ et al. ${ }^{24} \mathrm{~A}$ level of $P<0.0085$ was considered statistically significant.

\section{RESULTS}

Among all the subjects, cord blood adiponectin concentrations were higher in male than in female neonates $(42.2 \pm 28.3$ versus $34.7 \pm 19.0 \mu \mathrm{g} \mathrm{ml}^{-1}, P<0.01$ ), but the difference was not significant after adjustment for birth weight (Table 1). Adiponectin concentrations were also higher in neonates born by vaginal delivery than in those born by cesarean section $\left(39.7 \pm 23.2\right.$ versus $\left.33.0 \pm 22.4 \mu \mathrm{g} \mathrm{ml}^{-1}, P<0.01\right)$, but the difference was not significant after adjustment for birth weight. Cord blood adiponectin concentrations were positively related to gestational age $(r=0.14, P<0.01)$, birth weight $(r=0.23, P<0.01)$, birth weight s.d. score $(r=0.21, P<0.01)$, birth length $(r=0.13$, $P<0.01)$ and ponderal index $(r=0.15, P<0.01$; Table 2$)$. Maternal age, parity, pre-pregnant body mass index and placental weight were not correlated with cord blood adiponectin concentrations. A multiple

Table 1 Baseline characteristics of 526 neonates

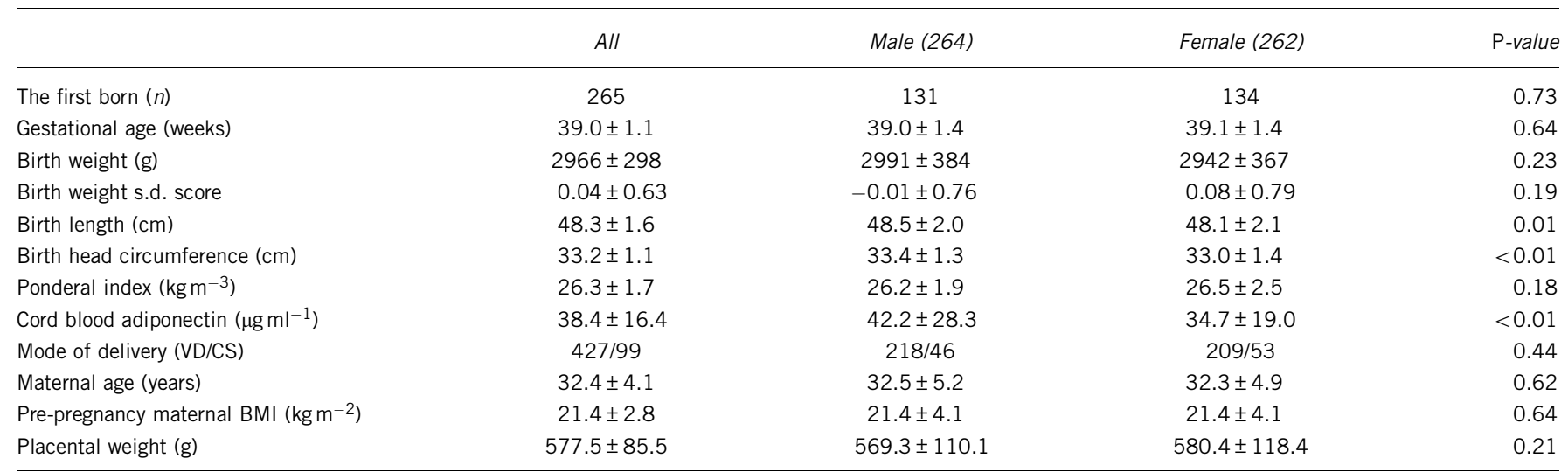

Abbreviations: BMI, body mass index; CS, cesarean section; VD, vaginal delivery.

Values are mean \pm s.d. 
regression analysis with the cord blood adiponectin as the dependent variable for all subjects revealed that birth weight s.d. score was independently associated with the cord blood adiponectin $(r=0.31$, $P<0.01)$.

Eight ADIPOQ SNPs were genotyped from the 526 DNA samples. Genotype counts are shown in Table 3. No significant deviation of the Hardy-Weinberg equilibrium was observed in all SNPs (rs266729, $P=0.61 ;$ rs182052, $P=0.60 ;$ rs710445, $P=0.78 ;$ rs16861205, $P=0.81$; rs12495941, $P=0.63 ;$ rs1501299, $P=0.40 ;$ rs3774261, $P=0.58$; and rs2082940, $P=1.00$ ). The associations between each SNP and birth weight s.d. score or cord blood adiponectin concentrations were analyzed (Tables 3 and 4). One SNP (rs266729) was found to be

Table 2 Correlation of adiponectin with baseline characteristics

\begin{tabular}{|c|c|c|}
\hline & r & P-value \\
\hline Gestational age (weeks) & 0.14 & $<0.01$ \\
\hline Birth weight $(\mathrm{g})$ & 0.23 & $<0.01$ \\
\hline Birth weight s.d. score & 0.21 & $<0.01$ \\
\hline Birth length $(\mathrm{cm})$ & 0.13 & $<0.01$ \\
\hline Birth head circumference $(\mathrm{cm})$ & 0.06 & 0.15 \\
\hline Ponderal index $\left(\mathrm{kg} \mathrm{m}^{-3}\right)$ & 0.15 & $<0.01$ \\
\hline Maternal age (years) & -0.02 & 0.72 \\
\hline Parity & 0.005 & 0.90 \\
\hline Pre-pregnancy maternal BMI $\left(\mathrm{kg} \mathrm{m}^{-2}\right)$ & 0.01 & 0.81 \\
\hline Placental weight (g) & -0.03 & 0.50 \\
\hline
\end{tabular}

Abbreviation: BMI, body mass index. significantly associated with birth weight s.d. score. The neonates carrying the rs $266729 \mathrm{G}$ allele had a significantly greater birth weight s.d. score than those homozygous for the $\mathrm{C}$ allele (CC: $-0.06 \pm 0.75$ versus CG: $0.20 \pm 0.64$ versus GG: $0.07 \pm 0.78 ; P=1.65 \times 10^{-3}$, adjusted $\left.P=9.90 \times 10^{-3}\right)$. However, this association was not significant after adjustment for cord blood adiponectin concentrations $(P=0.04$, adjusted $P=0.26$ ). The rs266729 SNP was also strongly associated with cord blood adiponectin concentrations; neonates with rs266729 GG had the highest adiponectin levels (CC: $34.1 \pm 20.2$ versus CG: $44.3 \pm 26.1$ versus GG: $54.1 \pm 36.7 \mu \mathrm{g} \mathrm{ml}^{-1}, P=2.80 \times 10^{-9}$, adjusted $\left.P=1.68 \times 10^{-8}\right)$. This association, furthermore, still remained significant after adjustment for birth weight s.d. score $\left(P=6.63 \times 10^{-8}\right.$, adjusted $\left.P=3.98 \times 10^{-7}\right)$.

\section{DISCUSSION}

This is the first study to investigate the relationship of ADIPOQ SNPs with both cord blood adiponectin concentrations and birth weight s.d. score in a relatively large sample size in the Asian population and to perform multivariable adjustment for potential confounders including maternal factors and perinatal characteristics. As cord blood adiponectin concentrations have been shown to be influenced by a variety of maternal complications in pregnancy, infants whose mothers had hypertension or diabetes mellitus, or whose mothers received antenatal glucocorticoids were excluded from our study subjects. ${ }^{12,25}$ Although we did not measure maternal blood adiponectin concentrations in the study, cord blood adiponectin has been shown not to be influenced by placenta or maternal circulation. ${ }^{8}$ Additionally, it has been known that cord blood adiponectin levels are not changed by parity or mode of delivery. ${ }^{25,26}$ As our previous study

Table 3 The association of SNPs with birth weight s.d. score

\begin{tabular}{|c|c|c|c|c|c|c|}
\hline \multirow[b]{2}{*}{$S N P I D$} & \multirow[b]{2}{*}{ Location } & \multirow[b]{2}{*}{ Genotype } & \multirow[b]{2}{*}{$\mathrm{n}$} & \multicolumn{3}{|c|}{ Birth weight s.d. score } \\
\hline & & & & & $\mathrm{P}$ (adjusted $\mathrm{P}$ ) & $\begin{array}{l}\text { Adjusted } \mathrm{P} \text { by cord blood } \\
\text { adiponectin (adjusted } \mathrm{P} \text { ) }\end{array}$ \\
\hline \multirow[t]{3}{*}{ rs266729 } & $5^{\prime}$ near gene & $\mathrm{CC}$ & 322 & $-0.06 \pm 0.75$ & $1.65 \times 10^{-3}$ & $0.04(0.26)$ \\
\hline & & CG & 182 & $0.20 \pm 064$ & $\left(9.90 \times 10^{-3}\right)$ & \\
\hline & & GG & 22 & $0.07 \pm 0.78$ & & \\
\hline \multirow[t]{3}{*}{ rs182052 } & Intron & $\mathrm{AA}$ & 133 & $-0.05 \pm 0.83$ & $0.67(1)$ & $0.50(1)$ \\
\hline & & $A G$ & 254 & $0.10 \pm 0.75$ & & \\
\hline & & GG & 134 & $-0.00 \pm 0.75$ & & \\
\hline \multirow[t]{3}{*}{ rs710445 } & Intron & $\mathrm{AA}$ & 83 & $0.06 \pm 0.72$ & $0.55(1)$ & $0.51(1)$ \\
\hline & & $A G$ & 252 & $0.05 \pm 0.74$ & & \\
\hline & & GG & 180 & $0.01 \pm 0.84$ & & \\
\hline \multirow[t]{3}{*}{ rs16861205 } & Intron & GG & 304 & $0.04 \pm 0.73$ & $0.81(1)$ & $0.84(1)$ \\
\hline & & $\mathrm{GA}$ & 192 & $0.04 \pm 0.84$ & & \\
\hline & & $\mathrm{AA}$ & 28 & $-0.02 \pm 0.80$ & & \\
\hline \multirow[t]{3}{*}{ rs12495941 } & Intron & $\mathrm{GG}$ & 215 & $-0.01 \pm 0.90$ & $0.25(1)$ & $0.23(1)$ \\
\hline & & GT & 240 & $0.06 \pm 0.77$ & & \\
\hline & & TT & 60 & $0.07 \pm 0.71$ & & \\
\hline \multirow[t]{3}{*}{ rs1501299 } & Intron & $\mathrm{CC}$ & 258 & $0.10 \pm 0.78$ & $0.11(0.66)$ & $0.10(0.59)$ \\
\hline & & $\mathrm{CA}$ & 226 & $-0.04 \pm 0.77$ & & \\
\hline & & $A A$ & 41 & $0.01 \pm 0.77$ & & \\
\hline \multirow[t]{3}{*}{ rs3774261 } & Intron & $\mathrm{AA}$ & 192 & $0.06 \pm 0.82$ & $0.61(1)$ & $0.53(1)$ \\
\hline & & $A G$ & 250 & $0.00 \pm 0.74$ & & \\
\hline & & GG & 72 & $0.04 \pm 0.83$ & & \\
\hline \multirow[t]{3}{*}{ rs2082940 } & 3' UTR & $\mathrm{CC}$ & 242 & $-0.02 \pm 0.77$ & $0.05(0.31)$ & $0.03(0.17)$ \\
\hline & & CT & 222 & $0.04 \pm 0.78$ & & \\
\hline & & TT & 51 & $0.29 \pm 0.84$ & & \\
\hline
\end{tabular}

Abbreviations: Adjusted $P$, adjusted by multiple comparison $P$; SNP, single-nucleotide polymorphism; UTR, untranslated region. 
Table 4 The association of SNPs with adiponectin concentration

Adiponectin $\left(\mu \mathrm{g} \mathrm{ml^{-1 } )}\right.$

\begin{tabular}{|c|c|c|c|c|c|c|}
\hline SNP ID & Location & Genotype & $\mathrm{n}$ & & $\mathrm{P}$ (adjusted $\mathrm{P}$ ) & Adjusted $\mathrm{P}$ by $B W$ (adjusted $\mathrm{P}$ ) \\
\hline & & CG & 182 & $44.3 \pm 26.1$ & $\left(1.68 \times 10^{-8}\right)$ & $\left(3.98 \times 10^{-7}\right)$ \\
\hline \multirow[t]{3}{*}{ rs182052 } & Intron & $\mathrm{AA}$ & 133 & $39.8 \pm 24.8$ & $0.27(1)$ & $0.23(1)$ \\
\hline & & $A G$ & 254 & $38.6 \pm 22.6$ & & \\
\hline & & GG & 134 & $36.7 \pm 22.8$ & & \\
\hline & & GG & 180 & $39.9 \pm 24.9$ & & \\
\hline \multirow[t]{3}{*}{ rs16861205 } & Intron & GG & 304 & $40.2 \pm 25.1$ & $0.04(0.22)$ & $0.04(0.22)$ \\
\hline & & GA & 192 & $36.4 \pm 20.3$ & & \\
\hline & & $A A$ & 28 & $33.3 \pm 17.1$ & & \\
\hline \multirow[t]{2}{*}{ rs12495941 } & Intron & GG & 215 & $39.0 \pm 24.6$ & $0.85(1)$ & $0.66(1)$ \\
\hline & & GT & 240 & $37.4 \pm 21.0$ & & \\
\hline \multirow[t]{3}{*}{ rs3774261 } & Intron & AA & 192 & $37.8 \pm 21.1$ & $0.63(1)$ & $0.55(1)$ \\
\hline & & $A G$ & 250 & $38.3 \pm 25.4$ & & \\
\hline & & GG & 72 & $39.4 \pm 21.0$ & & \\
\hline \multirow[t]{3}{*}{ rs2082940 } & $3^{\prime}$ UTR & $\mathrm{CC}$ & 242 & $39.8 \pm 25.6$ & $0.34(1)$ & $0.16(0.97)$ \\
\hline & & CT & 222 & $36.5 \pm 21.0$ & & \\
\hline & & $\mathrm{TT}$ & 51 & $38.9 \pm 19.8$ & & \\
\hline
\end{tabular}

Abbreviations: Adjusted $P$, adjusted by multiple comparison $P$; BW, birth weight; SNP, single-nucleotide polymorphism; UTR, untranslated region.

Data are expressed as mean \pm s.d.

showed that the serum adiponectin concentration on the first day of life was higher in AGA than in SGA term infants, SGA neonates were excluded from the present study. ${ }^{11}$

Recent studies have shown that cord blood adiponectin concentrations are correlated positively with birth weight, suggesting that fetal adiponectin levels are likely to influence fetal growth. $8,10,27,28$ MazakiTovi et al. ${ }^{29}$ have reported that the cord blood adiponectin concentration in the smaller neonate of discordant twins is lower than that in the larger counterpart. Our result showing that cord blood adiponectin concentrations were positively correlated with birth weight s.d. scores was in agreement with the results in previous studies. Furthermore, we confirmed previous findings of no gender difference in adiponectin levels. ${ }^{8,10,11,28}$ Serum adiponectin levels are known to be inversely correlated with body fat mass in adolescents and adults, whereas cord blood adiponectin concentrations are positively correlated with birth weight s.d. score, mostly determined by fat mass. ${ }^{1,30,31}$ This positive relationship between the two parameters in newborns may be explained by a lack of negative feedback on adiponectin production because of few hypertrophic adipocytes, an increased amount of fat mass together with an increased number of small adipocytes, low percentage of body fat with a different fat distribution and relatively abundant brown adipose tissue secreting adiponectin. , $32,33^{-3}$

In the study of ADIPOQ SNPs and cord blood adiponectin concentrations, Rothenbacher et al..$^{22}$ investigated associations of ADIPOQ SNPs (rs17300539, rs266729 and rs1501299) with cord blood adiponectin concentrations in neonates, most of whom were of German ethnicity, and showed that the subjects with rs266729 CG or GG genotype had higher cord blood concentrations of adiponectin than those with the CC genotype after adjustment for gender and gestational age; these findings were consistent with the present study. However, the relationship between the ADIPOQ SNPs and birth weight was not presented in the German study. ${ }^{22}$ The rs266729 SNP in the ADIPOQ promoter region has been shown to be independently associated with circulating adiponectin levels and to contribute to the risk of metabolic syndrome and type 2 diabetes. ${ }^{15,34,35}$ As rs266729 is located at one of the transcriptional stimulatory protein (SP1)binding sites, the rs266729 $\mathrm{G}$ allele is considered to alter the SP1binding function and consequently reduce adiponectin promoter activity. ${ }^{36}$ Previous studies reported that the plasma adiponectin levels did not differ between healthy lean adults with rs266729 GG and those with CC or CG. ${ }^{18,37}$ In our study, cord blood adiponectin concentrations were significantly higher in neonates with rs266729 GG than in those with CC/CG. This discrepancy may be explained by different biological mechanisms being involved in the production or regulation of adiponectin in fetal or neonates from those in children/adults. First, in the second half of intrauterine life, fetal adipose tissue rapidly expands with increasing size and number of adipocytes, and is mainly composed of small newly differentiated adipocytes, which secrete more adiponectin to increase adipocyte proliferation and lipid accumulation. ${ }^{33,38}$ Additionally, a negative feedback on adiponectin production caused by fat mass with hypertrophic adipocytes has not been found in newborns. Although further investigations are needed, the genetic effects of rs266729 SNP on adiponectin promoter activity is likely to alter adipose tissue metabolism in intrauterine life, unlike in adults. Second, because human neonates possess a relatively higher content of brown adipose tissue than adults, the adiponectin derived from brown adipose tissue in addition to white adipose tissue may contribute to the difference in circulating adiponectin levels between 
newborns and adults. Viengchareun et al. ${ }^{39}$ reported that strong expression of $A D I P O Q$ was observed in the brown adipose tissue of rats and mice, suggesting that brown adipocytes are capable of expressing $A D I P O Q$. To date, it is unclear whether the genetic regulation for adiponectin production differs between brown adipose tissue and white adipose tissue.

Fetal growth is a complex process depending on the genetics of the fetus, the availability of nutrients and oxygen to the fetus, maternal nutrition and various growth factors and hormones of maternal, fetal and placental origin. Although adiponectin is postulated to be a possible candidate contributing to both birth weight and insulin resistance, only one report is available on the genetic association between $A D I P O Q$ variants and birth weight. A case-control study in the Brazilian population demonstrated that the rs17300539 A allele in $A D I P O Q$ was significantly associated with an increased chance of large-for-gestational-age birth, but the study did not measure circulating adiponectin levels at birth. ${ }^{40}$ Because the rs17300539 A allele is very rare in Japanese (monoallelic in HapMap JPT and HapMap $\mathrm{CHB}$ ), we did not genotype rs17300539 in our study. ${ }^{41}$ We showed that the positive correlation between the rs266729 SNP in ADIPOQ and birth weight s.d. score in univariate analysis did not persist significantly after adjustment for cord blood adiponectin concentrations, indicating that the association is probably mediated by alterations of adiponectin as an insulin sensitizer.

In conclusion, we investigated the association between ADIPOQ SNPs and birth weight s.d. score and cord blood adiponectin concentrations for the first time in the Asian population, showing that the cord blood adiponectin concentrations were positively correlated with the birth weight s.d. score. In addition, rs266729 was significantly associated with cord blood adiponectin concentrations after adjustment for birth weight s.d. score, but not with birth weight s.d. score independently, suggesting that the influence of the $A D I P O Q$ variant on birth weight may be dependent on circulating adiponectin levels.

\section{ACKNOWLEDGEMENTS}

This work was supported by Grant-in-Aid for Scientific Research Grant-in-Aid for Young Scientists.

1 Arita, Y., Kihara, S., Ouchi, N., Takahashi, M., Maeda, K., Miyagawa, J. et al. Paradoxical decrease of an adipose-specific protein, adiponectin, in obesity. Biochem. Biophys. Res. Commun. 257, 79-83 (1999).

2 Weyer, C., Funahashi, T., Tanaka, S., Hotta, K., Matsuzawa, Y., Pratley, R. E. et al. Hypoadiponectinemia in obesity and type 2 diabetes: close association with insulin resistance and hyperinsulinemia. J. Clin. Endocrinol. Metab. 86, 1930-1935 (2001).

3 Maeda, N., Takahashi, M., Funahashi, T., Kihara, S., Nishizawa, H., Kishida, K. et al. PPARgamma ligands increase expression and plasma concentrations of adiponectin, an adipose-derived protein. Diabetes 50, 2094-2099 (2001).

4 Yamauchi, T., Kamon, J., Waki, H., Terauchi, Y., Kubota, N., Hara, K. et al. The fatderived hormone adiponectin reverses insulin resistance associated with both lipoatrophy and obesity. Nat. Med. 7, 941-946 (2001).

5 Schondorf, T., Maiworm, A., Emmison, N., Forst, T. \& Pfutzner, A. Biological background and role of adiponectin as marker for insulin resistance and cardiovascular risk. Clin. Lab. 51, 489-494 (2005).

6 Gluckman, P. D., Sizonenko, S. V. \& Bassett, N. S. The transition from fetus to neonatean endocrine perspective. Acta Paediatr. 88(Suppl), 7-11 (1999).

7 Fowden, A. L. The role of insulin in fetal growth. Early Hum. Dev. 29, 177-181 (1992).

8 Sivan, E., Mazaki-Tovi, S., Pariente, C., Efraty, Y., Schiff, E., Hemi, R. et al. Adiponectin in human cord blood: relation to fetal birth weight and gender. J. Clin. Endocrinol. Metab. 88, 5656-5660 (2003).

9 Chan, T. F., Yuan, S. S., Chen, H. S., Guu, C. F., Wu, L. C., Yeh, Y. T. et al. Correlations between umbilical and maternal serum adiponectin levels and neonatal birthweights. Acta. Obstet. Gynecol. Scand. 83, 165-169 (2004).

10 Tsai, P. J., Yu, C. H., Hsu, S. P., Lee, Y. H., Chiou, C. H., Hsu, Y. W. et al. Cord plasma concentrations of adiponectin and leptin in healthy term neonates: positive correlation with birthweight and neonatal adiposity. Clin. Endocrinol. (Oxf). 61, 88-93 (2004)
11 Kamoda, T., Saitoh, H., Saito, M., Sugiura, M. \& Matsui, A. Serum adiponectin concentrations in newborn infants in early postnatal life. Pediatr. Res. 56, 690-693 (2004).

12 Lindsay, R. S., Walker, J. D., Havel, P. J., Hamilton, B. A., Calder, A. A. \& Johnstone, F. D. Adiponectin is present in cord blood but is unrelated to birth weight. Diabetes Care. 26, 2244-2249 (2003).

13 Barker, D. J., Winter, P. D., Osmond, C., Margetts, B. \& Simmonds, S. J. Weight in infancy and death from ischaemic heart disease. Lancet 2, 577-580 (1989).

14 Barker, D. J., Hales, C. N., Fall, C. H., Osmond, C., Phipps, K. \& Clark, P. M. Type 2 (non-insulin-dependent) diabetes mellitus, hypertension and hyperlipidaemia (syndrome X): relation to reduced fetal growth. Diabetologia 36, 62-67 (1993).

15 Vasseur, F., Helbecque, N., Dina, C., Lobbens, S., Delannoy, V., Gaget, S. et al. Singlenucleotide polymorphism haplotypes in the both proximal promoter and exon 3 of the APM1 gene modulate adipocyte-secreted adiponectin hormone levels and contribute to the genetic risk for type 2 diabetes in French Caucasians. Hum. Mol. Genet. 11, 26072614 (2002).

16 Hara, K., Boutin, P., Mori, Y., Tobe, K., Dina, C., Yasuda, K. et al. Genetic variation in the gene encoding adiponectin is associated with an increased risk of type 2 diabetes in the Japanese population. Diabetes 51, 536-540 (2002).

17 Richardson, D. K., Schneider, J., Fourcaudot, M. J., Rodriguez, L. M., Arya, R., Dyer, T. D. et al. Association between variants in the genes for adiponectin and its receptors with insulin resistance syndrome (IRS)-related phenotypes in Mexican Americans. Diabetologia 49, 2317-2328 (2006).

18 Bouatia-Naji, N., Meyre, D., Lobbens, S., Seron, K., Fumeron, F., Balkau, B. et al. ACDC/adiponectin polymorphisms are associated with severe childhood and adult obesity. Diabetes 55, 545-550 (2006).

19 Nishida, H., Sakanoue, M., Kurachi, K., Asada, M., Kubo, S. \& Funakawa, H. Fetal growth curves of Japanese. Acta Pediatr. Japonica 20, 90-97 (in Japanese) (1984).

20 De Bakker, P. I., Yelensky, R., Pe'er, I., Gabriel, S. B., Daly, M. J. \& Altshuler, D. Efficiency and power in genetic association studies. Nat. Genet. 37, 1217-1223 (2005).

21 Barrett, J. C., Fry, B., Maller, J. \& Daly, M. J. Haploview: analysis and visualization of LD and haplotype maps. Bioinformatics 21, 263-265 (2005).

22 Rothenbacher, D., Nieters, A., Weyermann, M. \& Brenner, H. Adiponectin polymorphisms, cord blood levels of adiponectin, and body composition. J. Allergy Clin. Immunol. 120, 469-470 (2007).

23 Gonzalez, J. R., Armengol, L., Sole, X., Guino, E., Mercader, J. M., Estivill, X. et al. SNPassoc: an R package to perform whole genome association studies. Bioinformatics 23, 644-645 (2007).

$24 \mathrm{Li}, \mathrm{J}$. \& Ji, L. Adjusting multiple testing in multilocus analyses using the eigenvalues of a correlation matrix. Heredity 95, 221-227 (2005).

25 Kajantie, E., Hytinantti, T., Hovi, P. \& Andersson, S. Cord plasma adiponectin: a 20fold rise between 24 weeks gestation and term. J. Clin. Endocrinol. Metab. 89, 40314036 (2004).

26 Mazaki-Tovi, S., Kanety, H., Pariente, C., Hemi, R., Efraty, Y., Schiff, E. et al. Determining the source of fetal adiponectin. J. Reprod. Med. 52, 774-778 (2007).

27 Inami, I., Okada, T., Fujita, H., Makimoto, M., Hosono, S., Minato, M. et al. Impact of serum adiponectin concentration on birth size and early postnatal growth. Pediatr. Res. 61, 604-606 (2007)

28 Kotani, Y., Yokota, I., Kitamura, S., Matsuda, J., Naito, E. \& Kuroda, Y. Plasma adiponectin levels in newborns are higher than those in adults and positively correlated with birth weight. Clin. Endocrinol. (Oxf). 61, 418-423 (2004).

29 Mazaki-Tovi, S., Kanety, H., Pariente, C., Hemi, R., Yinon, Y., Wiser, A. et al. Adiponectin and leptin concentrations in dichorionic twins with discordant and concordant growth. J. Clin. Endocrinol. Metab. 94, 892-898 (2009).

30 Nemet, D., Wang, P., Funahashi, T., Matsuzawa, Y., Tanaka, S., Engelman, L. et al. Adipocytokines, body composition, and fitness in children. Pediatr. Res. 53, 148-152 (2003).

31 Yang, W. S., Lee, W. J., Funahashi, T., Tanaka, S., Matsuzawa, Y., Chao, C. L. et al. Weight reduction increases plasma levels of an adipose-derived anti-inflammatory protein, adiponectin. J. Clin. Endocrinol. Metab. 86, 3815-3819 (2001).

32 Korner, A. Wabitsch, M. Seidel, B., Fischer-Posovszky, P., Berthold, A., Stumvoll, M. et al. Adiponectin expression in humans is dependent on differentiation of adipocytes and down-regulated by humoral serum components of high molecular weight. Biochem. Biophys. Res. Commun. 337, 540-550 (2005).

33 Enzi, G., Zanardo, V., Caretta, F., Inelmen, E. M. \& Rubaltelli, F. Intrauterine growth and adipose tissue development. Am. J. Clin. Nutr. 34, 1785-1790 (1981)

34 Sun, H., Gong, Z. C., Yin, J. Y., Liu, H. L., Liu, Y. Z., Guo, Z. W. et al. The association of adiponectin allele $45 \mathrm{~T} / \mathrm{G}$ and $-11377 \mathrm{C} / \mathrm{G}$ polymorphisms with Type 2 diabetes and rosiglitazone response in Chinese patients. Br. J. Clin. Pharmacol. 65, 917-926 (2008)

35 Gong, M., Long, J., Liu, Q. \& Deng, H. C. Association of the ADIPOQ rs17360539 and rs266729 polymorphisms with type 2 diabetes: a meta-analysis. Mol. Cell. Endocrinol. 325, 78-83 (2010).

36 Zhang, D., Ma, J., Brismar, K., Efendic, S. \& Gu, H. F. A single nucleotide polymorphism alters the sequence of SP1 binding site in the adiponectin promoter region and is associated with diabetic nephropathy among type 1 diabetic patients in the Genetics of Kidneys in Diabetes Study. J. Diabetes Complications 23, 265-272 (2009).

37 Yang, M., Qiu, C. C., Chen, W., Xu, L. L., Yu, M. \& Xiang, H. D. Identification of a regulatory single nucleotide polymorphism in the adiponectin (APM1) gene 
associated with type 2 diabetes in Han nationality. Biomed. Environ. Sci. 21, 454-459 (2008).

38 Fu, Y., Luo, N., Klein, R. L. \& Garvey, W. T. Adiponectin promotes adipocyte differentiation, insulin sensitivity, and lipid accumulation. J. Lipid Res. 46, 13691379 (2005).

39 Viengchareun, S., Zennaro, M. C., Pascual-Le Tallec, L. \& Lombes, M. Brown adipocytes are novel sites of expression and regulation of adiponectin and resistin. FEBS Lett. 532, 345-350 (2002).
40 Bueno, A. C., Espineira, A. R., Fernandes-Rosa, F. L., De Souza, R. M., De Castro, M., Moreira, A. C. et al. Adiponectin: serum levels, promoter polymorphism, and associations with birth size and cardiometabolic outcome in young adults born large for gestational age. Eur. J. Endocrinol. 162, 53-60 (2010).

41 Populaire, C., Mori, Y., Dina, C., Vasseur, F., Vaxillaire, M., Kadowaki, T. et al. Does the -11377 promoter variant of APM1 gene contribute to the genetic risk for type 2 diabetes mellitus in Japanese families? Diabetologia 46, 443-445 (2003). 